International Journal of Learning, Teaching and Educational Research

Vol. 16, No. 10, pp. 18-26, October 2017

https://doi.org/10.26803/ijlter.16.10.2

\title{
A Cloze-styled Textual Enhancement Targeting Prepositions
}

\author{
Michael Heinz \\ Hankuk University of Foreign Studies \\ Seoul, South Korea
}

\begin{abstract}
Even at the highest level of bilingual competency for Korean learners of English, prepositions remain a significant challenge. Based on the classroom observation that incidental learning was not significantly improving proficiency with prepositions amongst a group of graduate school interpretation majors, a classroom exercise was executed as form of intervention. The participants in this study demonstrated very high proficiency in both English and Korean although all consider Korean to be their mother tongue. The exercise involved giving ten texts with Clozestyled textual enhancements to 33 students to determine if their proficiency with prepositions could be improved. Students were given a pretest and a post-test before and after the assignments respectively. The results were promising showing an average increase of $5.7 \%$ from pretest to post-test. Additional examination of the data showed that students of lower proficiency on average saw a $9.6 \%$ increase in scores. Qualitative feedback from students confirmed positive educational experiences and strongly supported the idea that incidental learning is insufficient. Further study is recommended based on the findings in this study.
\end{abstract}

Keywords: Cloze; Text Enhancement; Incidental Learning; EFL; SLA

\section{Introduction}

For Korean-speaking learners of English, preposition errors tend to persist even at the highest levels of bilingual competency. This can be a great source of frustration for those learners and can lead to a sense of hopelessness. At the highest levels most of these learners have already learned all of the rules related to prepositions and may even be able to execute them accurately on standardized tests. However in speaking tasks preposition errors often appear. Since most of the standard aspects of language learning have been exhausted already students look to find new methods. This study examines a particular teaching method utilized to improve preposition usage for English learners, but we must first look at what prepositions are before we can delve into how teaching them has been approached and how this study contributes. 
Unlike other aspects of language that can be somewhat superfluous or based purely on conventional usage, prepositions are grammatical words whose purpose is to help execute the essential grammatical goal of a sentence (Thornbury 2002). Moreover their prevalence is such that they appear in nearly all aspects of speaking and writing (Morenberg, 1997). Form, function and meaning can be used to classify prepositions. In terms of form they may be a simple one-word preposition, or they be contain two or more words making them complex prepositions. Single word prepositions are essentially fixed in the sense that new prepositions cannot be created whereas new complex prepositions are created with some frequency ((Grubic, 2004, cited in De Felice \& Pulman, 2008).

Prepositions in the English language are considered one of the most challenging grammatical features for L2 learners to master (Kao, 1999). Some have gone so far as to argue that the mastery of prepositions may be the greatest challenge that English learners face (Takahashi, 1969). EFL teachers and learners generally regard prepositions as taxing aspect of learning English due to the inconsistent ways in which they collocate with verbs requiring a considerable amount of memorization (Pittman, 1966). The rules for applying prepositions are not great in number and many prepositions themselves may possess a variety of functions (Swan, 1988).

It is against this backdrop that the current study was undertaken. Initially conceived of as a classroom activity to improve L2 learners' mastery of prepositions; the data collected from the students revealed some strong patterns which made it worthy of development. The current study examines the effect of using text enhancement in the form of a cloze test assignment utilizing authentic materials to see if students' mastery of prepositions could be improved.

\section{Literature Review}

Much of the impetus for this study began with classroom observations over several years that determined incidental learning to be insufficient in terms of meaningfully impacting mastery of prepositions. The researcher observed that preposition errors (and article errors) amongst students for whom Korean is their mother tongue persisted long after high bilingual capacity had been achieved. This is not surprising since incidental learning through extensive reading interventions has shown improvements mostly in vocabulary ((Brown et al., 2008; Cho and Krashen, 1994; Hayashi, 1999; Pigada and Schmitt, 2006; Rott, 1999; Sheu, 2003). Though some studies have shown some improvement in grammar as well (Sheu, 2003; Tudor and Hafiz, 1989). Overall it has been concluded that while incidental learning is not without merit, it is on the whole a process that is unpredictable and not particularly fast (Hulstijn et al., 1996; Paribakht and Wesche, 1999).

As such it has been asserted that input most be attended to with conscious deliberation with a particular need for the subjective experience of noticing to acquire greater linguistic sophistication (Schmidt 1990; Schmidt 1993; Schmidt 1994; Schmidt1995). Studies have established that there is link between learners' noticing of forms and successful learning (Robinson 1995; Skehan 1998). That noticing can take on many forms of textual enhancement that draws attention to particular 
language structures such as altering text by italicizing it, making it bold, underlining it, color coding it and so on (Cross, 2002). In order for this to be effective it may require a certain amount of frequency for the learner to actively notice the language structures' unique features (Swain, 1998).

Ellis (1997) with his focus on forms asserts that it is perfectly natural to attend to meaning before noticing form. Thus students of a new language are quick to key into content words and to guess based on context at the meaning of an utterance or sentence. Therefore things such as prepositions, articles or conjunction are often unconsciously disregarded initially. However with the help of a qualified L2 teacher, students can be brought to an awareness of these target language forms and in time students will come to grow and enhance their linguistic abilities.

Ellis (1997) asserts that this noticing of a grammatical feature is essential to acquire usage of it. Studies based on this assertions have looked at the role of textual enhancement and noticing and found promising results for rule-based linguistic forms (Fotos, 1991; Simard, 2009). Another study found a strong link between article acquisition and textual analysis (Ha, 2017). Two more studies found textual enhancement was helpful in the learning of phrasal verbs (Behzadhian, 2016; Ahmadi \& Panahandeh, 2016). Additionally, one study has even looked into the role of textual enhancement and the acquisitions of prepositions with findings that support the usage of such methods (Hassani, Azarnoosh, Naeini, 2015).

The current study wanted to see if noticing could be made more explicit and more effective by using textual enhancement that changed large numbers of authentic texts into Cloze tests. The research question being: if such texts were done in repetition many times would student proficiency increase?

\section{Test Subjects}

33 students in an interpretation and translation graduate school were identified as having persistent preposition errors despite possessing overall high fluency. None of the students in the present study considered their English to be at a native level. The students are considered to have high level bilingual capacity as the entrance exams for the graduate school seek to single out those abilities specifically. Standardized tests are not relied upon to assess students due to general distrust of their results in East Asia. Instead, students are given four essays to write: two in Korean and two in English. Numbers vary but typically the number of applicants is above 500 students minimally and may go as high as 1,000. Roughly 120 students are singled out based on their essay responses to go through an oral interview. During the interview students are expected to perform basic interpretation skills for English and Korean in both directions without preparation or note taking. The governing principle used to select the roughly 60 students that are selected is bilingual competency.

The researcher noted after years of teaching at this graduate school that despite the high bilingual competency possessed by the students, that their greatest number of errors occurred in the area of prepositions and articles. Corrective 
feedback whether immediate or delayed seemed not to make much of a difference which led to the formation of more direct approaches to correct these issues.

\section{Methodology}

The study was undertaken in the form of homework but careful data collection and promising results led to the development of this paper. As such certain flaws in the experimental design are obvious and cloud interpretations of the result but the results themselves do suggest the value of further study.

Students were given a pretest, homework and post-test all in the form of Cloze tests drawn up by parsing authentic speeches for some of the most common prepositions. Authentic texts were selected because they are thought to be more effective as teaching tools and tend to be more engaging (Guariento and Morley, 2001; Mishan, 2004) Texts for the pretest, homework, and post-test were all draw from speeches with subject matter that is common to the students such as presidential addresses by then U.S. President Barrack Obama or talks about economics.

The texts were parsed using the "replace all" function common to text software. In this case the author wrote a bit of java script to hasten the process but the "replace all" function in software such as Microsoft Word or Google docs would work just as well. The prepositions: "From," "On," "With," “To," "In," "By," "At," and "For" were selected as being representative of the most commonly occurring prepositions and as the items often misused by the students. Prepositions were replaced in one of two ways. The first stage was to replace prepositions such as "of" or "to" with an empty parenthesis block liking like this: ( ). The second stage employed on the tests and the homework was to parse the texts so that the existence or position of the aforementioned prepositions could not ascertained. Instead student would have to make sense of the sentence and include prepositions wherever they thought they were necessary.

The pretest and post-test were identical and consisted of 72 questions in which the position of a missing preposition was indicated and a second text in which 72 prepositions had been removed but their number, and position were not known to the student. Placing a preposition where no preposition should was valued as a loss of a point so it was possible to achieve a negative score on the second half of the pretest or post-test. Two samples are given below to illustrate what the pretest looked like:

Section 1 (Missing prepositions' positions are indicated)

It's an honor ( ) be back ( ) the American Legion. ( ) the story（ ) your service we see the spirit ( ) America. When your country needed you most, you stepped forward.

Section 2 (Missing prepositions' are not indicated)

And more broadly, the crisis Iraq underscores how we have meet today's evolving terrorist threat. The answer is not send large-scale military deployments that overstretch our military, and lead us occupying countries a long period time, and end up feeding extremism. 
After student pretest results were scored and collected, students were given access to a database of speeches parsed in the manner of both sections of the pretest/post-test. Students were given the originals as well and tasked with repetitively taking the Cloze worksheets to the point of mastery. Students were given 10 weeks to work on 10 worksheets at their leisure and were not observed therefore the level of student engagement cannot be accurately measured. However, the students were all graduate school students who tend to show high level study habits and motivation.

\section{Results}

The average score on the pretest for the 33 participants was 103.5 out of a possible score of 142 (Standard deviation=8.99), which means they displayed an accuracy rate of $72.9 \%$ and showed some variance in test score average. The average score on the post-test was 111.6 out of a possible score of 142 (Standard deviation=6.56), which means they displayed an accuracy of $78.6 \%$ with a slight reduction in score variance. So the reported increase in proficiency on average was $5.7 \%$. A t-test revealed that the results were statistically significant.

Overall the method can be seen as successful with some qualifications. First and foremost there was no control group so the results lack external validity. Moreover, the homework of the students was not monitored and as such the effort put into the process itself cannot be verified when considering all participants. The final concern is that the pretest and the post-test were identical so some of the improvement seen in the data could have resulted from familiarity with the test document, however the students were not shown the correct answers after they took the pretest.

When looking at the data a pattern was clear beyond the overall results. Students who scored above 105 (73.9\%) on the pretest showed generally no improvement between pretest and post-test or in many cases actually had a reduced score. Conversely students who scored below 105 saw greater improvements in the scores overall. For this low scoring group the pretest average was $97.5(68.7 \%)$ and their average post-test score was $111.3(78.3 \%)$, so overall an increase of $9.6 \%$ in terms of proficiency.

After the data had been collected and analyzed qualitative feedback was generated in terms of in-depth discussions with the students in which a number of affirming comments were made about the process. Overall students reported learning a lot about prepositions through the process and the general feedback was positive about the learning outcomes. Many said that they broke long term patterns that they had not been aware of previously. Generally students with lower levels of bilingual competency were more positive about the homework. Some students admitted to not taking the homework as seriously as they might have and lamented not having the time to do so. All agreed that it was time consuming process which is one of the definite downsides to this technique. Additionally all students agreed that the text enhancement in which the placement of prepositions is unknown was a much harder task than simply engaging the Cloze-styled text enhancement. 
One of the more interesting and encouraging comments was about the text selection. One student was certain that the researcher had selected texts that mirrored the questions on the exams so that we would learn the proper collocations for certain prepositions. Many students agreed with this comment feeling that the texts were selected with some pattern as to preposition usage. It was this comment that led the researcher to move towards publishing this data because absolutely no consideration was given to which prepositions occurred in each homework text. Instead texts were chosen purely on the basis of authenticity and relevance.

\section{Discussion}

Considering $5.7 \%$ increase in proficiency on average or the $9.6 \%$ increase seen amongst the less proficient students, either way the results are modest but not insignificant. What is encouraging about these results however comes from the anecdotal experience researcher which is that generally students do not appear to approve in this area of proficiency over time within the program. There may be an extent to which this approach can improve students and it may be that more arduous direct instruction may need to accompany this kind of activity.

The comment made by a student regarding the apparent patterns between the homework and the tests that he thought was intentional, may provide some insight into the learning that takes place in this process and seems not to be occurring during incidental learning. The general agreement with that students' comment suggests that students did not realize that the placement of prepositions and their natural collocations were passing before their eyes all the time. These texts were in no way unusual for them to read or interpret/translate into Korean. These students read as many five such texts every day and dissect them for meaning vigorously. This may be a very strong indicator that incidental learning is wholly insufficient for this particular issue. It is conversely a strong endorsement of textual enhancement and for the notion that learners seek out meaning independent of form.

There is a serious question posed by the data that either reveals a need for greater controls in future studies or suggests a learning plateau of some importance. The fact that in general the students who scored lower on the pretest scored considerably higher relative scores on the post-test cannot be properly accounted for. It is entirely possible that students with higher proficiency (though there were no scores on the pretest or post-test above 85\%) did not aggressively engage the homework assignments because they did not feel they had much to learn. It could also be that students with high proficiency are somewhat negatively affected by this kind of exercise and it may cause them to overthink their responses in the quest for perfection. An additional possibility is that there was a smaller gap to close for the higher proficiency students so improvements they may have made may need to be interpreted as smaller steps forward given that an overall improvement in scores did occur. 


\section{Future Studies}

This study serves in many ways as a preliminary study for a much more thorough examination of this Cloze-styled text enhancement. A future study is being planned that can examine this technique with a proper control group and an additional group distinction that compares the Cloze-styled text enhancement with and without direct instruction about prepositions. For such a study a number of variables remain to be determined.

One of the most significant drawbacks of the current study was the lack of control over student work. By having the students do the work as homework there was no way to determine if they were legitimately repeating exercises to the point of relative mastery. It is entirely likely that some or many students did not engage the texts given to them more than once or twice before moving on. Any future study should find a way to keep the students under observation as they complete assignments.

One variable of additional concern is text selection. The current study opted for an authentic text but this comes with a number of drawbacks. First, there was no way to control for the types of prepositions that were in each of texts. Thus it was possible that many of the homework texts did not prepare the students to take the post-test. On other hand student feedback seems to suggest otherwise fairly strongly. Yet with some measure of control or even some editing of an authentic text there such enhancement may better streamline the learning process.

Another variable that was left unaccounted for was the differences between learning impact of the two forms of text enhancement used in the study. Students noticed a difference in terms of difficulty but not enough serious discussion occurred about the perceived differences in learning that came from the different textual enhancements. A future study would need to decide if both should be included, or only one, or conversely a third one might be added such as colorcoding prepositions read in a similar text before engaging the other forms of textual enhancement.

\section{Conclusion}

Overall this pilot study contains a number of imperfections that occurred due to its not having been launched as a study but merely as a classroom activity. The findings are still suggestive of strong possibilities given the ease with which the process can be replicated using any modern form of document software. Much of this classroom activity grew out of the realization that Cloze tests could be created in massive quantities with just a little software-based manipulation of texts. Still a larger and better designed study is needed to determine the significance of many of this studies' findings. 


\section{References}

Ahmadi, Badri F \& Panahandeh, E. (2016). The Role of Input-based and Output-based Language Teaching in Learning English Phrasal Verbs by Upper-intermediate Iranian EFL Learners. Journal of Education and Learning. Vol. 10 (1) pp. 22-33. doi: https://doi.org/10.11591/edulearn.v10i1.2860

Behzadian, Khatareh (2016) The Effect of Input Enhancement and Concordance-based Activities on Iranian EFL Learners' Acquisition and Retention of Phrasal Verbs. Michigan Academician: 2016, Vol. 44, No. 1, pp. 29-50. doi: https://doi.org/10.7245/0026-2005-44.1.29

Brown R, Waring R, Donkaewbua S (2008) Incidental vocabulary acquisition from reading, reading-while-listening, and listening to stories. Reading in a Foreign Language 20(2): 136-63.

Cho KS, Krashen SD (1994) Acquisition of vocabulary from the Sweet Valley Kids series: adult ESL acquisition. Journal of Reading 37(8): 662-67.

Cross, J. (2002). Noticing in SLA: Is it a valid concept? TESL-EJ, 6 (3). from: http://www.writing.berkeley.edu/TESL-EJ/ej23/a2.html

De Felice, R., \& Pulman, S. (2008). Automatic error detection in non-native English. Journal of CALICO, 26(3), 512-528.

Ellis, R. (1997). Second Language Acquisition. Oxford: Oxford University Press. doi: https://doi.org/10.1017/s0272263100014479

Fotos, S., \& Ellis, R. (1991). Communicating about grammar: A task-based approach. TESOL Quarterly, 25, 605-628. doi: https:// doi.org/10.2307/3587079

Guariento, W. and J. Morley. 2001. 'Text and task authenticity in the EFL classroom'. ELT Journal 55/4: 347-53. doi: https://doi.org/10.1093/elt/55.4.347

Ha, Jong-Bum (2017) Integration of Formal Instruction and Textual Enhancement in the Learning of English Articles. The Joongwon Linguistic Society of Korea, 44, 355377. doi: https:// doi.org/10.17002/sil..44.201707.355

Hassani M, Azarnoosh M \& Naeini J (2015). The Role of Noticing and Input Enhancement on the Acquisition of English Prepositions. International Journal of Language and Applied Linguistics, 1 (4), 47-52.

Hayashi K (1999) Reading strategies and extensive reading in EFL classes. RELC Journal 30(2): 114-32. doi: https:/ / doi.org/10.1177/003368829903000207

Hulstijn JH, Hollander M, Greidanus T (1996) Incidental vocabulary learning by advanced foreignnlanguage students: the influence of marginal glosses, dictionary use, and reoccurrence of unknown words. The Modern Language Journal 80(3): 327-39. doi: https:// doi.org/10.1111/j.1540-4781.1996.tb01614.x

Kao, C. C. (1999). An Investigation into lexical, grammatical, and semantic errors in English compositions of college students in Taiwan. Fu Hsing Kang Journal, 67, 1-32.

Mishan, F. 2004. 'Authenticating corpora for language learning: a problem and its resolution'. ELT Journal 58/3: 219-27. doi: https:// doi.org/10.1093/elt/58.3.219

Morenberg, M. (1997). Doing grammar (2nd ed.). New York: Oxford University Press.

Paribakht TS, Wesche M(1996) Enhancing vocabulary acquisition through reading: a hierarchy of text-related exercise types. Canadian Modern Language Review 52(2): 155-78.

Pigada M, Schmitt N (2006) Vocabulary acquisition from extensive reading: a case study. Reading in a Foreign Language 18(1): 1-28.

Pittman, G. A. (1966). Activating the use of prepositions. London: Longman.

Robinson, P. (1995). Attention, memory, and the "noticing" hypothesis. Language Learning, 45, 283-331. doi: https:// doi.org/10.1111/j.1467-1770.1995.tb00441.x 
Rott S (1999) The effect of exposure frequency on intermediate language learners' incidental vocabulary acquisition and retention through reading. Studies in Second Language Acquisition 21(04): 589-619. doi: https://doi.org/10.1017/s0272263199004039

Schmidt, R. (1990). The role of consciousness in second language learning. Applied Linguistics, 11, 12958. doi: https://doi.org/10.1093/applin/11.2.129

Schmidt, R. (1994). Deconstructing consciousness in search of useful definitions for applied linguistics. In J. Hulstiyn and R, Schmidt (eds): Consciousness in Second Language Learning. AILA Review, 11, 11-26.

Schmidt, R. (1995). Consciousness and foreign language learning: A tutorial on the role of attention and awareness in learning. In R. Schmidt (Ed.), Attention and awareness in foreign language learning (pp. 1-63). Hawai" ${ }^{\mathrm{e}}$ : Second Language Teaching \& Curriculum Center.

Skehan, P. (1998). A Cognitive Approach to Language Learning. Oxford: Oxford University Press.

Sheu SPH (2003) Extensive reading with EFL learners at beginning level. TESL Reporter 36: 8-26.

Simard, D. (2009). Differential effects of textual enhancement formats on intake, System, 37, 124-135. doi: https:// doi.org/10.1016/i.system.2008.06.005

Swain, M. (1998). Focus on form through conscious reflection. In C. Doughty, \& J. Williams (Eds.), Focus on form in classroom second language acquisition (pp. 6481). New York: Cambridge University Press.

Takahaski, G. (1969). Perception of space and the function of certain English prepositions. Language Learning. 19, 217-234. doi: https://doi.org/10.1017/s0272263100281059

Thornbury, S. (2002). How to teach vocabulary. Essex: Longman.

Tudor I, Hafiz F (1989) Extensive reading as a means of input to L2 learning. Journal of Research in Reading 12(2): 164-78. doi: https://doi.org/10.1111/j.14679817.1989.tb00164.x 